\title{
A municipalização do ensino no Chile*
}

\section{Municipal management of teaching in Chile}

\author{
I-Juca-Pirama Camargo Gil ${ }^{* *}$
}

\begin{abstract}
RESUMO
O texto é fruto de minha Dissertação de Mestrado sobre a mesma temática. Apresenta uma breve discussão teórica sobre a descentralização educacional, em especial na América Latina, e em seguida analisa a experiência chilena. Esta foi, durante décadas, considerada exemplar para a região e mesmo para outros cantos do mundo por órgãos como o Banco Mundial. Por meio de dados referentes a matrículas, números de professores por aluno, qualidade do ensino, financiamento, entre outros, discuto que há mais dúvidas que certezas sobre os efeitos positivos da descentralização levada a efeito no Chile.
\end{abstract}

Palavras-chave: descentralização, reformas educacionais.

\begin{abstract}
This text is fruit of my Master's degree Dissertation on the theme. It presents a short theoretical discussion about education decentralization, mainly in Latin America, and soon afterwards it analyzes the Chilean experience. This was considered, during decades, by international organisms as World Bank, as an example to Latin America and other places of the world. Based on data regarding registrations, numbers of teachers for student, quality of teaching,

* $\quad$ Este artigo é baseado em meu trabalho de mestrado. Ver GIL (2000).

** Pedagogo, professor na Universidade de Taubaté e na Fundação Santo André e doutorando pela Faculdade de Educação da USP. Para críticas, dúvidas, sugestões e elogios favor entrar em contato com jucagil@uol.com.br
\end{abstract}


financing, among other information, I consider that there are more doubts than certainties on the positive effects of decentralization improved by Chile.

Key-words: decentralization, education reforms.

\section{Por que o Chile?}

No momento em que o Brasil implanta novos mecanismos de financiamento educacional, em especial o Fundo de Manutenção e Desenvolvimento do Ensino Fundamental e Valorização do Magistério (Fundef) - induzindo o aprofundamento do processo de descentralização, consubstanciado na municipalização do ensino fundamental - analisar experiências de outros países pode contribuir para o aprimoramento de nossos debates.

A educação chilena foi e ainda é aclamada por organismos internacionais, incluindo o Banco Mundial, como uma experiência latino-americana bem sucedida, em especial devido a sua ação descentralizadora/ municipalizadora. Acredito que conhecer outras realidades, como a chilena, deve nos fazer refletir acerca dos rumos que o Brasil vem tomando. Considero estarmos incorrendo em equívocos desnecessários que poderiam ser evitados caso não buscássemos inventar a roda e olhássemos mais ao nosso redor, para nossos vizinhos. Nossos governantes são férteis em construir mitos, cabendo a nós a busca de olhares menos simplistas do que geralmente somos levados a ter.

Este artigo busca trazer informações acerca da experiência chilena, especialmente no que tange à evolução histórica das matrículas, à qualidade da educação e aos mecanismos de financiamento, questionando o papel exemplar que lhe é imputado. 


\section{Conhecendo nosso vizinho}

O Chile é tido como uma democracia consolidada, possuindo indicadores socioeconômicos superiores à média da região e, em alguns aspectos, bastante parecidos com os do chamado primeiro mundo. Ao contrário do Brasil, que é uma República Federativa, o Chile é um país unitário. Esta organização se caracteriza como sendo inerentemente mais propensa à centralização, visto que não possui entes políticos como os estados brasileiros ou norte-americanos. Assim, o referido país é constituído por 335 comunas/ municípios, dos quais cerca de 60\% têm até 20 mil habitantes. Podemos considerá-lo um país pequeno, visto que contava aproximadamente com 14 milhões de habitantes, em 1995, o que para nós brasileiros, lembra mais a população de um estado (o Paraná possuía cerca de 9,5 milhões de pessoas em seu território, em 2000).

O sistema educacional chileno é sub-dividido em educação pré-básica, ${ }^{1}$ geral básica, média e superior. A educação pré-básica não é obrigatória e atende a crianças de 0 a 5 anos. A educação geral básica possui oito anos de educação obrigatória, seriada, destinada a alunos dos 6 aos 13 anos. $^{2}$ A educação média tem quatro anos de duração e não é obrigatória, destinada a alunos de 14 a 18 anos.

O sistema educacional chileno se auto-intitula descentralizado, devido ao fato da administração dos estabelecimentos ser realizada por pessoas ou instituições municipais e particulares, denominadas mantenedoras, ${ }^{3}$ que assumem ante o Estado (governo central) a responsabilidade de manter em funcionamento os estabelecimentos educacionais. O sistema é composto por estabelecimentos subvencionados (municipais e particulares), privados - que atendem alunos dos níveis de educação pré-básica, geral básica e média - e corporações de administração delegada que atendem primordialmente à educação média técnico-profissional. ${ }^{4}$

1 denominada também de "parvularia".

2 É importante lembrar aos leitores brasileiros que, segundo a legislação brasileira vigente, educação básica inclui a educação infantil (creches e pré-escolas), o ensino fundamental (antigo $1 .^{\circ}$ grau) e o ensino médio (antigo 2. ${ }^{\circ}$ grau). Assim, a denominada educação básica chilena (mas também de muitos outros países latino-americanos) equivale ao ensino fundamental brasileiro.

3 O termo original é "sostenedor".

4 Estas escolas têm administração privada via convênio, contando com financiamento público fora do sistema de subvenções, que se verá adiante. 


\section{Um povo educado e uma grande rede privada}

Em 1998, as matrículas em educação geral básica alcançavam uma cobertura de $96 \%$, em educação média $82 \%$ e em educação pré-básica de $13,8 \% .^{5} \mathrm{O}$ analfabetismo entre a população de 15 anos, ou mais, era de $4,7 \%$, mas já ao final do regime militar, em 1990, somente cerca de 6,3\% da população era analfabeta. É relevante lembrar que já há quase trinta anos a ampla maioria dos chilenos tem acesso à educação básica, sendo que em 1970 este nível de ensino atingia 93\% da população. Ou seja, o regime militar, implantado em 1973, herdou uma população com acesso à educação bem próxima da universalização.

Em 1999, os níveis de educação pré-básica, básica e média possuíam cerca de 3,4 milhões de alunos. Cerca de 54\% destes estavam matriculados em escolas municipalizadas, $35 \%$ em particulares subvencionadas, 9\% em particulares pagas e $2 \%$ em corporações de administração delegada.

As matrículas de educação pré-básica apresentavam uma divisão por dependência administrativa em que $48 \%$ eram municipais e $35 \%$ particulares subvencionadas. É fundamental assinalar o aumento da presença proporcional da rede particular paga se comparada a sua participação no total geral das matrículas, atingindo cerca de $17 \%$ dos alunos da educação prébásica. Porém, levando-se em conta problemas de coleta de dados assumidos pelo Ministério da Educação (Mineduc), estas informações ficam prejudicadas em sua credibilidade.

As escolas particulares subvencionadas eram as grandes provedoras do atendimento de educação especial (68\%). Outro fato importante a ressaltar é que quase a totalidade dos atendimentos se dava na rede subvencionada, restando à rede paga menos de $1 \%$ do total.

A educação básica possuía cifras muito próximas à divisão proporcional da média geral relativa a todos os níveis agrupados. Os únicos aspectos dignos de nota são que a rede municipal atendia cerca de $57 \%$ das matrículas (pouco mais que sua média geral do total de matrículas) e que as corporações apresentavam poucos alunos neste nível. Por fim, a educação

5 Os dados da educação pré-básica são referentes às escolas subvencionadas municipalizadas ou particulares, Junji e Integra. Existem também estabelecimentos privados, dos quais o governo central não tem informações estatísticas; é alegada falta de legislação que facilite o acesso aos dados. 
média possuía cerca de metade de suas matrículas na rede municipal e é importante ressaltar a participação mais expressiva das corporações, cerca de $7 \%$.

TABELA 1- MATRÍCULAS POR NÍVEL E MODALIDADE, SEGUNDO DEPENDÊNCIA ADMINISTRATIVA - 1999

\begin{tabular}{c|c|c|c|c|c|c|c|c|c|c}
\hline & \multicolumn{2}{|c|}{ total } & \multicolumn{2}{c|}{ municipal } & \multicolumn{2}{c|}{ part. subv. } & \multicolumn{2}{c}{ part. paga } & \multicolumn{2}{c}{ corporação } \\
\cline { 2 - 11 } & Absol. & $\%$ & Absol. & $\%$ & Absol. & $\%$ & Absol. & $\%$ & Absol. & $\%$ \\
\hline total & 3.429 .927 & 100 & 1.866 .991 & 54,4 & 1.202 .327 & 35,1 & 306.591 & 8,9 & 54.018 & 1,6 \\
\hline pré-básica & 274.587 & 100 & 132.119 & 48,1 & 95.207 & 34,7 & 47.261 & 17,2 & 0 & 0,0 \\
\hline especial & 46.049 & 100 & 17.455 & 37,9 & 28.502 & 61,9 & 92 & 0,2 & 0 & 0,0 \\
\hline Básica & 2.305 .459 & 100 & 1.318 .389 & 57,2 & 806.514 & 35,0 & 180.345 & 7,8 & 211 & 0,0 \\
\hline Média & 803.832 & 100 & 399.028 & 49,6 & 272.104 & 33,9 & 78.893 & 9,8 & 53.807 & 6,7 \\
\hline
\end{tabular}

FONTE: MINEDUC, 1997.

NOTA: disponível na internet (http://www.mineduc.cl).

Outra informação importante para nos aproximarmos da realidade educacional chilena é a referente ao nível socioeconômico dos estudantes de cada uma das dependências administrativas. Assim, são apresentados dados da educação básica e básica especial, agrupados em cinco grandes grupos, sendo que o grupo I corresponde ao nível de renda mais baixo e o $\mathrm{V}$ ao mais alto.

TABELA 2 - CONDIÇÃO SOCIOECONÔMICA DOS ESTUDANTES DE EDUCAÇÃO BÁSICA E BÁSICA ESPECIAL ENTRE A POPULAÇÃO DE 0 A 24 ANOS, SEGUNDO DEPENDÊNCIA ADMINISTRATIVA

\begin{tabular}{c|c|c|c|c|c|c|c}
\hline & \multicolumn{2}{|c|}{ Total } & I & II & III & IV & V \\
\hline & $\mathrm{n}^{\mathbf{0}}$ & $\%$ & $\%$ & $\%$ & $\%$ & $\%$ & $\%$ \\
\hline Total & 2.351 .687 & 100 & 32,9 & 24,6 & 17,5 & 14,0 & 11,0 \\
\hline sem dado & 3.922 & 0,2 & 24,4 & 20,6 & 12,8 & 20,5 & 21,7 \\
\hline municipal & 1.354 .330 & 57,6 & 43,0 & 27,2 & 16,5 & 9,7 & 3,6 \\
\hline part. subv. & 796.102 & 33,9 & 23,5 & 25,5 & 21,8 & 20,0 & 9,1 \\
\hline part. paga & 196.623 & 8,4 & 1,8 & 3,0 & 6,5 & 18,9 & 69,8 \\
\hline Corporações & 710 & 0,0 & 28,9 & 29,0 & 24,5 & 17,6 & 0,0 \\
\hline
\end{tabular}

FONTE: MIDEPLAN, 1998.

Na tabela acima, os dados do Ministério do Planejamento (Mideplan) informam que, em 1998, 57,6\% dos alunos de educação básica e básica especial estavam em escolas municipais, $33,9 \%$ em particulares subvencionadas e $8,4 \%$ em particulares pagas. Ao verificarmos a divisão dos alunos entre as diferentes dependências administrativas, segundo o nível de renda, 
percebemos que a condição socioeconômica parece dividir a população nas redes de ensino. Assim, mais de $70 \%$ dos alunos municipais são das duas camadas mais pobres da população, enquanto na rede particular subvencionada esta cifra cai para $49 \%$ e, na particular paga, para $4,8 \%$. Por outro lado, apenas 13,3\% dos alunos que freqüentavam as escolas municipais pertenciam às duas camadas com maiores rendimentos, enquanto nas escolas particulares subvencionadas estes representavam $29,1 \%$ e, nas particulares pagas, $88,7 \%$. Consideramos estes dados fundamentais para compreender a política de descentralização implantada.

\section{Descentralização como municipalização e privatização educacional}

As críticas ao centralismo do Estado chileno existem desde o início do século XX e medidas de desconcentração precedem ao regime ditatorial, que teve início em 1973. Entendemos que o governo da Ditadura deu grande impulso a este debate e às medidas efetivas de desconcentração e descentralização em vários setores, incluindo o educacional.

Questão de extrema relevância é a relação entre o chamado processo de descentralização educacional no Chile e a privatização. Os dados indicam que ações para incentivar o crescimento da iniciativa privada são anteriores às medidas de descentralização explícitas. Digo explícitas, porque a própria privatização será interpretada posteriormente como uma das modalidades de descentralização, ao lado da municipalização. No entanto, existe a opinião de que a municipalização foi pensada originariamente como um estágio intermediário, e acessório, para a privatização completa do sistema. Há indicações também de que dentro do governo ditatorial houve disputas com relação a esta questão, seja na opção entre privatização e municipalização, ou sobre o ritmo e a forma da privatização.

Em 1976, foi promulgada a Lei Orgânica de Municípios e da Administração Comunal, quando os municípios tiveram suas atribuições alteradas, deixando de ser órgãos geradores de políticas para serem considerados executores de políticas de níveis hierarquicamente superiores. Os alcaldes, chefes dos governos municipais, passavam a ser indicados diretamente pelo presidente do país e aos municípios não era atribuída a administração da educação formal. 
A municipalização do ensino iniciou-se efetivamente em janeiro de 1980 e o repasse de responsabilidades foi rápido. Em abril de 1982, cerca de $84 \%$ das escolas já haviam sido transferidas. No entanto, problemas econômicos adiaram o andamento da municipalização, que só foi retomada e concluída em 1986.

Mas o que se pretendia com a municipalização? Os objetivos declarados para a municipalização do ensino eram os seguintes:

- possibilitar maior participação da comunidade local, democratizando a gestão;

- melhorar a administração do sistema educacional, tornando-o mais eficiente;

- melhorar a qualidade do ensino, também tomado como fator de eficácia;

- gerar maior igualdade de oportunidades educacionais a todas as crianças em idade escolar e aumentar a cobertura nos setores de pobreza, em especial, na educação pré-básica e básica. Este objetivo também é citado como sendo o que proporcionaria a eqüidade educacional;

- aumentar o gasto público em educação;

- aumentar a renda e as perspectivas trabalhistas do setor docente.

Como podemos notar, os objetivos declarados não diferem muito dos citados em outras experiências, inclusive a brasileira. Porém, alguns autores apontam como objetivos implícitos da municipalização a tentativa de tirar poder político dos docentes, isolando-os, e o de privatização total do sistema.

\section{Descentralização em dados: o império privado é urbano}

O chamado processo de descentralização chileno consistiu na saída do governo central (fiscal) da administração direta das escolas, transferindo seus estabelecimentos para os municípios e possibilitando o crescimento da iniciativa privada no setor.

Enfocando a evolução histórica da quantidade de estabelecimentos escolares em cada dependência administrativa fica evidente a tendência de privatização do sistema educacional chileno. 
TABELA 3 - ESTABELECIMENTOS ESCOLARES, SEGUNDO DEPENDÊNCIA ADMINISTRATIVA - 1980/1999

\begin{tabular}{c|c|c|c|c|c|c|c|c|c|c|c|c}
\hline \multirow{2}{*}{ ano } & \multicolumn{2}{|c|}{ total } & \multicolumn{2}{c|}{ fiscal } & \multicolumn{2}{c|}{ municipal } & \multicolumn{2}{c|}{ part. subv. } & \multicolumn{2}{c|}{ part. paga } & \multicolumn{2}{c}{ Corpor. } \\
\cline { 2 - 14 } & Absol. & $\%$ & Absol. & $\%$ & Absol. & $\%$ & Absol. & $\%$ & Absol. & $\%$ & Absol. & $\%$ \\
\hline 1980 & 8.799 & 100 & 6.370 & 72,4 & 0 & 0,0 & 1.627 & 18,5 & 802 & 9,1 & 0 & 0 \\
\hline 1990 & 9.814 & 100 & 0 & 0,0 & 6.288 & 64,1 & 2.694 & 27,5 & 759 & 7,7 & 73 & 0,7 \\
\hline 1999 & 10.705 & 100 & 0 & 0,0 & 6.290 & 58,8 & 3.170 & 29,6 & 1.175 & 11,0 & 70 & 0,7 \\
\hline
\end{tabular}

FONTE: MINEDUC, 1997. Organização do autor.

NOTA: disponível na internet (http/www.mineduc.cl).

Com estes dados se pode concluir que, entre 1980 e 1999, o número total de estabelecimentos educacionais cresceu 22\%, havendo 1.906 escolas a mais que no início do período. A desigualdade aparece ao se observar que, em 1999, a rede municipal apresentava 80 escolas a menos que a rede fiscal de 1980, correspondendo a um decréscimo de 1\%, e os estabelecimentos particulares subvencionados tinham crescido em 1.543 estabelecimentos em relação a 1980, representando um crescimento de praticamente $100 \%$. No período analisado, as escolas particulares pagas também cresceram, aumentando em 373 estabelecimentos se comparado aos números de 1980 , o que significou um avanço de $46 \%$.

Isto fez com que a participação relativa da rede fiscal/municipalizada caísse de $72 \%$ em 1980, para 59\% em 1999. De outro lado, as redes particular subvencionada e paga aumentaram sua participação relativa, no mesmo período, de $18 \%$ para $30 \%$ e de $9 \%$ para $11 \%$, respectivamente. As corporações se expandiram nos anos 80 e depois se mantiveram estáveis.

Ao contrário do que o senso comum poderia supor óbvio, os governos democráticos foram os que mais favoreceram o crescimento de escolas particulares, tanto as subvencionadas quanto - e principalmente - as pagas. No entanto, o crescimento das diferentes redes de escolas não foi uniforme em termos territoriais. Como as regiões rurais tinham menor concentração populacional e, no geral, população com menor poder aquisitivo, coube ao poder público, por meio das escolas municipais, oferecer educação nestas áreas. Os municípios administravam, em 1999, cerca de 82\% das escolas rurais chilenas, enquanto as escolas particulares subvencionadas representavam $18 \%$, as pagas $0,4 \%$ e as corporações $0,2 \%$. Nas zonas urbanas, a situação era bem diferente e as cifras, respectivamente $40 \%$, $39 \%, 19 \%$ e $1 \%$. 
TABELA 4 - ESTABELECIMENTOS EDUCACIONAIS, POR DEPENDÊNCIA ADMINISTRATIVA E ZONA - 1999

\begin{tabular}{c|c|c|c|c|c|c|c|c|c|c}
\hline \multirow{2}{*}{} & \multicolumn{2}{|c|}{ total } & \multicolumn{2}{c|}{ municipal } & \multicolumn{2}{c|}{ part. subv. } & \multicolumn{2}{c|}{ part. paga } & \multicolumn{2}{c}{ Corp. } \\
\cline { 2 - 11 } & Absol. & $\%$ & Absol. & $\%$ & Absol. & $\%$ & Absol. & $\%$ & Absol. & $\%$ \\
\hline total & 10750 & 100 & 6290 & 58,5 & 3170 & 29,5 & 1175 & 10,9 & 70 & 0,7 \\
\hline urbano & 5950 & 100 & 2409 & 40,5 & 2325 & 39,1 & 1156 & 19,4 & 60 & 1,0 \\
\hline rural & 4755 & 100 & 3881 & 81,6 & 845 & 17,8 & 19 & 0,4 & 10 & 0,2 \\
\hline
\end{tabular}

FONTE: MINEDUC, 1997. Organização do autor.

NOTA: disponível na internet (http://www.mineduc.cl).

Dos dados apresentados na tabela pode-se deduzir que a zona rural não oferece possibilidades de lucro que interesse ao setor privado, pois se considerado o total de escolas municipais, $62 \%$ estavam na zona rural e apenas $27 \%$ das particulares subvencionadas e $2 \%$ das pagas estavam em setores rurais.

\section{Matrículas: a privatização é ainda maior}

Entre 1981 e 1999, as matrículas chilenas tiveram um acréscimo de 588.201 alunos, ou cerca de $21 \%$. Como no caso do número de estabelecimentos, as matrículas também tiveram movimentos desiguais, se analisadas do ponto de vista de cada uma das dependências administrativas. Mais uma vez, a rede fiscal/municipalizada abre espaço ao setor particular e, neste caso, de forma e em proporções mais generosas. No período, as matrículas fiscais/municipalizadas diminuíram em 348.982 alunos, o que representou uma queda de aproximadamente $16 \%$. Em termos relativos, a participação desta dependência no total de matrículas caiu de $78 \%$ para $54 \%$.

Dessa forma, a rede particular cresceu bastante. As matrículas particulares pagas tiveram um aumento de 57\%, entre 1981 e 1999, enquanto as particulares subvencionadas cresceram $179 \%$ no mesmo período! 
TABELA 5 - EVOLUÇÃO MATRÍCULAS CRIANÇAS/JOVENS CHILENOS, POR DEPENDÊNCIA ADMINISTRATIVA - 1981/1999

\begin{tabular}{c|c|c|c|c|c|c|c|c|c|c|c|c}
\hline Anos & \multicolumn{2}{|c|}{ Total } & \multicolumn{2}{c|}{ Fiscal } & \multicolumn{2}{c|}{ Municipal } & \multicolumn{2}{c|}{ Part.Sub. } & \multicolumn{2}{c|}{ Part. Paga } & \multicolumn{2}{c}{ Corp. } \\
\hline & Absol. & $\%$ & Absol. & $\%$ & Absol. & $\%$ & Absol. & $\%$ & Absol. & $\%$ & Absol. & $\%$ \\
\hline 1981 & 2.841 .726 & 100 & 2.215 .973 & 78,0 & 0 & 0,0 & 430.232 & 15,1 & 195.521 & 6,9 & 0 & 0,0 \\
\hline 1987 & 2.962 .755 & 100 & 0 & 0,0 & 1.797 .953 & 60,7 & 910.968 & 30,7 & 196.200 & 6,6 & 57.634 & 1,9 \\
\hline 1990 & 2.963 .139 & 100 & 0 & 0,0 & 1.717 .222 & 58,0 & 960.460 & 32,4 & 228.205 & 7,7 & 57.252 & 1,9 \\
\hline 1996 & 3.270 .614 & 100 & 0 & 0,0 & 1.828 .022 & 55,9 & 1.080 .412 & 33,0 & 309.468 & 9,5 & 52.712 & 1,6 \\
\hline 1999 & 3.429 .927 & 100 & 0 & 0,0 & 1.866 .991 & 54,4 & 1.202 .327 & 35,1 & 306.591 & 8,9 & 54.018 & 1,6 \\
\hline
\end{tabular}

FONTE: MINEDUC, 1997. Organização do autor.

NOTA: disponível na internet (http/www.mineduc.cl).

\section{Qualidade do ensino: as desigualdades permanecem}

O quadro abaixo mostra a evolução histórica dos resultados dos testes de qualidade (Programa de Evaluación del Rendimento - PER e seu sucessor Sistema de Medición de la Calidad de la Educación - Simce), nas diferentes disciplinas entre as dependências administrativas. Os números são relativos à porcentagem média de respostas corretas nas provas realizadas nos $4^{\circ}$ e $8^{\circ}$ anos da educação básica, entre 1988 e 1997.

TABELA 6 - CASTELHANO

\begin{tabular}{|c|c|c|c|c|c|c|c|c|c|c|}
\hline \multirow{2}{*}{$\begin{array}{c}\text { Dep. } \\
\text { Administrativa }\end{array}$} & \multicolumn{5}{|c|}{$4^{\circ}$ ano } & \multicolumn{5}{|c|}{$8^{\circ}$ ano } \\
\hline & 1988 & 1990 & 1992 & 1994 & 1996 & 1989 & 1991 & 1993 & 1995 & 1997 \\
\hline Municipal & 50,2 & 57,2 & 64,0 & 63,4 & 68,2 & 53,0 & 52,8 & 55,1 & 55,8 & 62,1 \\
\hline Part. Subvenc. & 58,0 & 54,4 & 70,7 & 69,9 & 74,2 & 58,8 & 57,0 & 61,1 & 61,1 & 68,4 \\
\hline Part. Pago & 79,0 & 80,0 & 86,8 & 83,7 & 86,1 & 76,7 & 72,6 & 76,8 & 74,6 & 80,4 \\
\hline
\end{tabular}

TABELA 7 - MATEMÁTICA

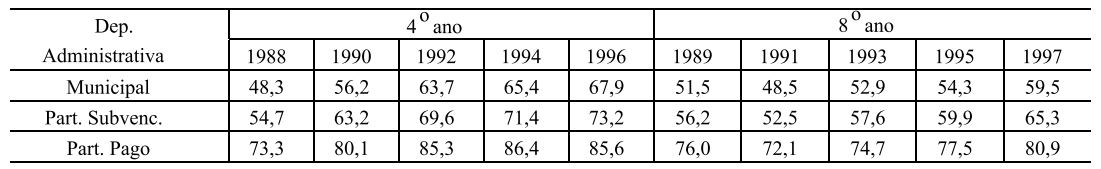


TABELA 8 - HISTÓRIA E GEOGRAFIA

\begin{tabular}{|c|c|c|c|c|c|c|c|c|c|c|}
\hline \multirow{2}{*}{$\begin{array}{c}\text { Dep. } \\
\text { Administrativa }\end{array}$} & \multicolumn{5}{|c|}{$4^{\circ}$ ano } & \multicolumn{5}{|c|}{$8^{\circ}$ ano } \\
\hline & 1988 & 1990 & 1992 & 1994 & 1996 & 1989 & 1991 & 1993 & 1995 & 1997 \\
\hline Municipal & 54,2 & 56,7 & 60,8 & 58,0 & 65,3 & 54,7 & 49,6 & 53,3 & 56,7 & 61,5 \\
\hline Part. Subvenc. & 58,1 & 61,9 & 66,7 & 60,8 & 67,8 & 57,1 & 54,8 & 57,7 & 61,0 & 68,4 \\
\hline Part. Pago & 74,9 & 73,8 & 79,4 & 71,9 & 78,1 & 76,3 & 68,8 & 68,7 & 74,0 & 80,4 \\
\hline
\end{tabular}

TABELA 9 - CIÊNCIAS NATURAIS

\begin{tabular}{|c|c|c|c|c|c|c|c|c|c|c|}
\hline \multirow{2}{*}{$\begin{array}{c}\text { Dep. } \\
\text { Administrativa }\end{array}$} & \multicolumn{5}{|c|}{$4^{\circ}$ ano } & \multicolumn{5}{|c|}{$8^{\circ}$ ano } \\
\hline & 1988 & 1990 & 1992 & 1994 & 1996 & 1989 & 1991 & 1993 & 1995 & 1997 \\
\hline Municipal & 50,2 & 57,0 & 56,1 & 64,4 & 65,6 & 56,5 & 47,8 & 50,9 & 55,7 & 59,7 \\
\hline Part. Subvenc. & 55,3 & 63,4 & 62,5 & 67,5 & 69,0 & 57,9 & 52,3 & 55,0 & 60,1 & 63,7 \\
\hline Part. Pago & 73,5 & 77,8 & 76,3 & 78,0 & 81,4 & 77,2 & 67,1 & 68,3 & 75,1 & 76,1 \\
\hline
\end{tabular}

FONTE: MINEDUC, 1998. Organização do autor.

Verifica-se que em todas as dependências administrativas, em todas as disciplinas e nas duas séries em questão, houve evolução dos resultados entre o primeiro e o último ano da série - com exceção dos resultados de ciências naturais da rede particular paga do $8^{\circ}$ ano. Analisando os dados das escolas subvencionadas (municipais e particulares), notaremos que algumas diferenças de resultados foram ampliadas e outras diminuídas, não parecendo haver grandes mudanças no sentido de diminuir a desigualdade entre ambas, ou entre estas e a rede particular paga. A este respeito um estudo de Carnoy e Mac Ewan, analisando estes dados, afirma que "as escolas particulares subvencionadas são menos eficazes que as municipais quanto aos resultados em espanhol e matemática para grupos de estudantes similares" (CARNOY; MACEWAN, 1998, p. 2).

Por desconhecer a metodologia utilizada e não ser este o objeto principal deste trabalho, não se emitirá juízo sobre o fato destas provas serem ou não bons fatores de análise da qualidade de ensino. $\mathrm{O}$ fato é que eram as únicas informações disponíveis, não existindo outros tipos de estudos específicos sobre o tema. 


\section{Financiamento da educação: apoio ao avanço privado}

As informações referentes ao financiamento da educação no Chile são importantes para enriquecer as análises sobre a administração do sistema e, em específico, como esta poderia ter influenciado a descentralização educacional no país.

As principais fontes de financiamento do sistema escolar eram o aporte fiscal - advindo do Mineduc mediante da chamada subvenção de escolaridade - , o financiamento compartido, os aportes municipais e as cobranças que realizam os estabelecimentos privados.

O principal aporte fiscal era a subvenção de escolaridade, existente desde 1951. Este modelo de financiamento delegava aos pais a decisão de escolher o estabelecimento em que seus filhos estudariam. Esta decisão definia o destino dos recursos do Estado. Assim, a subvenção de escolaridade era enviada mensalmente para os estabelecimentos municipalizados e particulares relacionados a esta modalidade de financiamento conforme o número de alunos que freqüentavam às aulas. Esta subvenção era efetivada conforme um fator denominado Unidade de Subvenção Escolar (USE). O valor das subvenções em USE diferia de acordo com o tipo de ensino (prébásica, básica, média, adultos, especial etc.), tipos de escola (diurna, vespertina), região geográfica e ruralidade, buscando refletir assim as diferenças nos custos do ensino. $\mathrm{O}$ aporte que cada estabelecimento recebia mensalmente, por subvenção de escolaridade, era calculado com base na média de presença dos seus alunos na escola nos últimos três meses, sendo que as subvenções correspondentes aos meses de janeiro e fevereiro eram pagas pela média de presença do ano anterior.

O financiamento compartido foi uma política implantada em 1990, que previa a possibilidade de que ao financiamento fiscal das escolas subvencionadas se somasse a cobrança de mensalidades dos pais. Até 1993, esta política estava restrita às escolas particulares, sendo que os mantenedores é que escolhiam livremente aderir ou não à política. As escolas que aderissem eram autorizadas a cobrar até 2,5 USE dos pais e, neste caso, sofreriam uma redução linear de $40 \%$ no repasse de suas subvenções.

A partir de 1993, as escolas municipais de educação média foram incluídas, porém para aderir a tal política deveriam ter o aval dos pais; as 
escolas municipais de educação básica estavam excluídas deste esquema, permanecendo gratuitas. As alterações realizadas neste período criaram também reduções escalonadas da subvenção conforme o valor da mensalidade cobrada dos pais. Assim, as escolas que cobrassem até 0,5 USE não teriam nenhum corte em suas subvenções, as que cobrassem algo entre 0,5 e 1 USE sofreriam corte de $10 \%$ em suas subvenções e assim por diante, conforme a tabela abaixo. As escolas somente perderiam o direito à subvenção caso cobrassem valores superiores a 4 USE.

A adesão à nova política foi muito rápida na rede particular. Nota-se que, já em 1994, o número de alunos da rede particular subvencionada que passou a utilizar o financiamento compartido correspondia a mais da metade do total de estudantes desta dependência administrativa. Em 1997, o financiamento compartido já atingia $69 \%$ dos alunos destas escolas. As escolas municipais estavam aderindo numa velocidade bem mais lenta, sendo que o total de alunos atingidos por esta política, em 1997, representava apenas $16,5 \%$ do total de alunos do nível médio municipal.

TABELA 10 - MATRÍCULAS EM FINANCIAMENTO COMPARTIDO POR DEPENDÊNCIA ADMINISTRATIVA - 1993/1997

\begin{tabular}{c|c|c|c|c|c|c}
\hline \multirow{2}{*}{ Ano } & \multicolumn{2}{|c|}{ Total } & \multicolumn{2}{c|}{ municipal } & \multicolumn{2}{c}{ part. subv. } \\
\cline { 2 - 7 } & Absol. & $\%$ & Absol. & $\%$ & Absol. & $\%$ \\
\hline 1993 & 142.732 & 100 & 0 & 0 & 142.732 & 100 \\
\hline 1994 & 534.261 & 100 & 17.787 & 3,3 & 516.474 & 96,7 \\
\hline 1995 & 672.334 & 100 & 40.008 & 6,0 & 632.326 & 94,0 \\
\hline 1996 & 745.289 & 100 & 48.315 & 6,5 & 696.974 & 93,5 \\
\hline 1997 & 822.368 & 100 & 63.536 & 7,7 & 758.832 & 92,3 \\
\hline
\end{tabular}

FONTE: MINEDUC, 1998. ORGANIZAÇÃO DO AUTOR.

Destaque-se ainda que o financiamento dos estabelecimentos particulares pagos provinha integralmente das mensalidades cobradas dos pais. 


\section{Descentralização? Pero no mucho...}

Com base tanto nas caracterizações internacionais quanto nas chilenas do que seria descentralização (delegação de poder entre instâncias juridicamente independentes e autônomas entre si), pode-se dizer que ela não ocorreu, de fato, no sistema educacional do Chile. O que o governo militar de Pinochet fez ao transferir compulsoriamente as escolas sob sua responsabilidade para as municipalidades seria melhor definido como desconcentração, visto que os municípios não eram autônomos. Quando assumiu o governo, democraticamente eleito, e os municípios ganharam autonomia política, verifica-se que o governo nacional manteve sob seu poder a ampla maioria das questões essenciais ao direcionamento do sistema, incluindo os recursos financeiros, o que tornou os municípios, na prática, dependentes do governo central.

Vale lembrar que o governo central ainda dita a linha da política educacional, implementa os programas de reforma, determina os valores das subvenções, negocia questões trabalhistas, incluindo os salários, avalia e financia diretamente grande parte do sistema. Entende-se assim, que a descentralização chilena foi uma estratégia político-administrativa utilizada como recurso para a implementação de um processo de privatização gradual do sistema.

O processo de privatização pode ser entendido com duas vertentes complementares. A mais perceptível seria a de propiciar o crescimento das redes particulares de ensino, via subvenção e via omissão ou lentidão no atendimento às demandas por vagas, deixando que o setor privado tivesse o mercado educacional ao seu dispor, sem um concorrente estatal forte. A segunda vertente, e talvez a mais importante, seria a de privatizar a lógica de funcionamento do sistema educativo. Nesse sentido, teria envolvido as escolas municipais numa disputa por verbas com as particulares subvencionadas, incumbindo os pais de fazerem a seleção natural das melhores e mais aptas a sobreviverem no mercado.

No entanto, sabe-se agora que esta concorrência não aconteceu como o previsto, uma vez que as escolas municipais não recebiam recursos diretamente do Mineduc como as particulares subvencionadas. Os órgãos municipais responsáveis pela administração educacional é que recebiam os recursos e os utilizavam, filtrando os impactos de possíveis alterações para cada uma das escolas; em outras palavras, as escolas muitas vezes não sofriam com o aumento ou diminuição de vagas. 


\section{Participe... pagando!}

Quanto à pretendida participação da comunidade local ou democratização da gestão, pode-se afirmar que os pais não foram integrados às discussões e deliberações, principalmente quando estas se referiam à gestão dos estabelecimentos e ao uso de recursos financeiros.

No entanto, o direito potencial dos pais poderem ameaçar retirada de seus filhos das escolas, e estas, conseqüentemente, perderem parte das subvenções que recebiam como uma forma de participação, pode ser entendida como aumento de poder. Alguns analistas entendem ainda, que a contribuição financeira para com os estabelecimentos escolares seria uma forma de participação e, com estes dois argumentos, indicam, como resultado, um aumento da participação.

É fundamental que se considere que a descentralização educacional chilena não foi uma conquista de sua sociedade e sim uma imposição de um governo ditatorial, sem negociações, sem debates com a população, sendo uma estratégia de racionalização do papel do Estado. Aumento de participação, neste contexto, possui um significado muito peculiar...

\section{A suposta eficiência descentralizada}

Com relação à maior eficiência que teria a gestão descentralizada, os dados disponíveis indicam que este objetivo não foi alcançado. Teria havido duplicação de funções entre os órgãos desconcentrados e as municipalidades, crescimento do aparato burocrático, tráfico de influência, corrupção, desvio de recursos educacionais, entre outros problemas.

Outro fato lembrado freqüentemente é que os municípios não foram preparados para assumir as responsabilidades educacionais a eles delegadas e que nem posteriormente houve ação reparadora neste sentido. Há forte indicação de que teria sido indispensável a formação de pessoal, a reorganização administrativa e a disponibilização de recursos materiais e financeiros condizentes com a nova situação, além de facilitar processos de integração dos trabalhos entre os municípios. 
Outro mito ligado à descentralização chilena é o de que a gestão privada seria necessariamente mais competente que a pública. Porém, não foram encontrados indicadores que demonstrassem esta suposta superioridade.

\section{Mais educação média (privada, principalmente). E as criancinhas...???}

Não se encontraram também informações claras que permitissem considerações sobre o objetivo do processo de descentralização relativo ao aumento da cobertura educacional das camadas socioeconômicas mais baixas da população referente à educação pré-básica e básica. De forma paralela, diversos autores afirmam que a desigualdade não tem decrescido ou vem aumentando, mas não mencionam as fontes de suas inferências, o que indica que a proclamada eqüidade - ou igualdade - não vem sendo atingida.

$\mathrm{O}$ que se pode afirmar no que concerne à cobertura educacional, considerando não somente o ensino obrigatório, é que após o processo de municipalização/privatização do sistema educacional chileno, o atendimento da educação média aumentou em proporções bastante expressivas. Devido ao fato de que, mesmo antes de 1980, o país já havia praticamente universalizado o acesso à educação obrigatória (básica), pode-se supor que o crescimento do nível médio fosse uma conseqüência natural ou que poderia ocorrer mesmo sem as mudanças de 1980 em diante. Ou seja, talvez não se possa creditar, numa razão direta, o aumento da cobertura do ensino médio à descentralização. De qualquer forma, a descentralização não foi um impeditivo de tal expansão. O que pode ser questionado é a estagnação destes níveis de cobertura há cerca de uma década.

Já o aumento da cobertura da educação pré-básica foi bastante tímido, porém esta afirmação fica prejudicada pela ausência de dados confiáveis sobre as escolas particulares, que de modo bastante contraditório com relação ao funcionamento do restante do sistema, parecem estar desregulamentadas, não tendo que prestar contas aos órgãos públicos e 
não sendo, por estes, supervisionadas. Este fato permite suspeitar que os últimos governos - ou mesmo a população chilena - não deram a devida atenção a este nível de ensino.

\section{Qualidades continuam sendo qualidades}

A esperada melhoria da qualidade do ensino também não se efetivou da forma esperada, segundo os analistas (COLÉGIO DE PROFESSORES DO CHILE, 1997; EGAÑA, 1999; HÉVIA, 1999). Estes autores baseiam suas avaliações principalmente, quando não exclusivamente, nas medições realizadas por meio do desempenho dos alunos em provas nacionais. Nestas, os alunos das escolas particulares se destacam, sendo seguidos pelos alunos dos estabelecimentos particulares subvencionados e, por último, pelos estudantes das escolas municipalizadas. A análise destes resultados leva, muitas vezes, à defesa da lógica de administração privada para explicar o melhor desempenho das escolas particulares entre as subvencionadas, argumentando que estas trariam maiores retornos com os mesmos recursos.

Ao argumento de que o nível socioeconômico dos alunos das escolas particulares subvencionadas era mais alto do que o das escolas municipalizadas, explicando a discrepância, são citados estudos em que as particulares continuariam obtendo melhores resultados, mesmo controlando a variável socioeconômica.

\section{O constante apoio financeiro favorecendo a iniciativa privada}

A política de financiamento educacional chilena, via subvenções, vem sendo mantida, em sua lógica geral, há cerca de 20 anos, o que pode ser pouco tempo para países do chamado primeiro mundo, mas não necessariamente entre os países em desenvolvimento, onde a descontinuidade tem sido uma regra. Independentemente do mérito interno da atual política, é de 
se supor que sua constância no tempo tenha gerado credibilidade e possibilitado o planejamento em médio ou longo prazos, indispensáveis para políticas educacionais, onde os resultados não são imediatos.

Outro ponto interessante da política educacional chilena em relação ao projeto de financiamento é que este possui mecanismos para respeitar as distintas realidades da educação. Este fato é relevante se considerarmos ainda que, apesar do discurso de que é necessário respeitar a diversidade, os organismos internacionais difundem políticas homogeneizantes e os governos adotam práticas por vezes pouco flexíveis. E argumentam que esta opção facilita avaliar impactos em âmbito nacional, criar rankings, premiar os exitosos, punir os incompetentes etc. Neste sentido, os valores diferenciados das subvenções educacionais por nível e modalidade, assim como os mecanismos de suplementação para zonas mais pobres e rurais, por exemplo, são formas alternativas para buscar a equalização de oportunidades. Estas últimas podem ser consideradas, em última análise, propostas de discriminação positiva.

No entanto, outro ponto citado como fator de desigualdade (iniqüidade) era o uso da frequiência dos alunos às escolas como critério para determinar os valores dos repasses de subvenções. Isto fazia com que setores mais pobres e rurais, dentre outros, em épocas de chuvas ou de colheita tivessem suas verbas drasticamente reduzidas, pela baixa frequiência dos alunos. Argumenta-se que este mecanismo punia exatamente aqueles que mais necessitavam de recursos extras.

A implantação do financiamento compartido conseguiu trazer novos aportes de recursos para o setor educacional, por meio do pagamento de mensalidades pelas famílias. No entanto, consolidou o modelo de privatização, dando um incentivo extra aos empresários do ensino, que puderam ter seus valores, por aluno, acrescidos em até quatro vezes sem perder as subvenções governamentais. Admitido este fato, as tradicionais denominações dos mantenedores das escolas chilenas perdem sentido, pois enquanto somente as particulares pagas não eram gratuitas a divisão era nítida, porém agora as particulares subvencionadas também cobram das famílias, alterando o quadro. Talvez fosse mais correto agrupar as escolas em gratuitas (as municipais) e pagas (as particulares, sub-divididas em subvencionadas e

6 Coalisão de centro-esquerda que assumiu o poder após o fim da ditadura e se mantém no governo até hoje. 
não-subvencionadas). Importante lembrar que o financiamento compartido foi implantado já após o fim do governo ditatorial, sob vigência da democracia. Esta teria sido uma condição imposta pelos oposicionistas ligados ao antigo regime para a aprovação de propostas do governo da Concertación, ${ }^{6}$ atuantes no poder legislativo do país.

\section{Apesar de você, amanhã há de ser outro dia...}

Embora o governo militar tenha perseguido violentamente seus opositores, as forças sindicais do setor educacional resistiram aos embates e conseguiram manter-se como agentes sociais ativos e considerados como legítimos interlocutores de sua categoria. As mobilizações por elas lideradas levaram à reconquista de diversos direitos dos docentes, incluindo um piso salarial nacional. É indicado também que a maior parte dos professores sofreu perda de direitos trabalhistas. O Colegio de Profesores de Chile, agremiação com funções sindicais que representa os docentes em nível nacional, foi e ainda é contrário à descentralização educacional e cobra do governo central a retomada de funções mais ativas sobre o sistema educacional.

A qualidade do ensino também não atingiu níveis expressivamente superiores na descentralização/privatização. Deve-se considerar a hipótese de que os recursos disponíveis para a educação, principalmente para as escolas municipais, sejam, de fato, insuficientes. Na ausência de estudos que indiquem de forma consistente qual seria um suposto custo-alunoqualidade $^{7}$ aceitável, pode-se utilizar outros indicadores como o do esforço social considerado justo para viabilizar o ensino. O financiamento compartido, por exemplo, indica de forma implícita que uma educação de qualidade pode custar até quatro vezes mais o que o governo vem pagando como subvenção. Acreditando que o governo não chegou a esta proporção com o objetivo único de que os empresários do ensino tivessem maiores lucros,

7 O debate brasileiro sobre financiamento educacional, pelo menos desde 1995, inclui o conceito de custo-aluno-qualidade que seria o montante de recursos necessários para oferecer ensino de qualidade, tendo como base o custo de cada aluno em um ano de estudos. 
podemos dizer que o Chile considera justo, digno e aceitável que a obtenção da qualidade possa pressupor multiplicar por quatro os atuais níveis de investimento.

Sabemos que os valores das subvenções não são baseados em nenhum estudo de custo. Eles demonstram simplesmente o que os diferentes governos consideraram razoável ou possível de ser pago, mediados pelas pressões dos atores sociais em prol de mais recursos para que o setor pudesse oferecer um ensino de qualidade. Assim, poderíamos dizer que o valor das subvenções educacionais chilenas obedecem antes a um cálculo político do que a pareceres técnicos sobre a quantia necessária para uma almejada qualidade de ensino.

\section{Centralizando conclusões}

Como foi visto, a descentralização/muncipalização foi e ainda é usada também como um subterfúgio retórico para a implantação de políticas de desresponsabilização dos governos centrais para com ações antes sob sua jurisdição. Após manterem políticas inconsistentes e irresponsáveis, alguns governantes passaram a defender que a saída seria por via da iniciativa privada e não pela ação pública e muito menos estatal.

O debate e as políticas sobre descentralização parecem vir buscando responsabilizar cada vez mais as extremidades inferiores dos sistemas, cada vez distanciando-se mais dos governos centrais, passando do município às escolas, aos pais, a cada professor individualmente, a cada cidadão que deveria doar algum apoio ao ensino. Quem sabe em breve teremos defensores de que a melhor forma de gerir a educação seria quando cada sala de aula tivesse seus recursos próprios e buscasse alternativas solidárias ${ }^{8}-\mathrm{e}$ solitárias - para a solução de seus problemas.

$8 \mathrm{O}$ apelo à solidariedade, à livre iniciativa, à boa vontade, às ações filantrópicas surgem como alternativa à atuação do Poder Público. Afasta-se o campo educacional do âmbito dos direitos e passa-se ao do assistencialismo. 
A experiência chilena é importante pela sua duração no tempo e pela abrangência nacional da distribuição de recursos via subvenções. Porém, se entendermos um modelo como algo digno de admiração, a descentralização educacional do Chile, com o que ela passou a simbolizar, é apenas um mito.

Quaisquer que sejam os diferentes aspectos considerados em nenhuma de suas hipóteses ela significou, de forma consistente e satisfatória, democratização da gestão educacional, melhoria substancial da qualidade do ensino, aumento dos gastos educacionais públicos ou redução de desigualdades entre as regiões ou pessoas mais pobres com relação as de melhor condição socioeconômica; ou seja, não realizou de forma satisfatória nenhum dos milagres que lhe imputam.

No mais, devemos considerar entre as dificuldades para se avançar no debate sobre a descentralização educacional (como sempre, incluindo a municipalização), por um lado, o fato dos governos latino-americanos não demonstrarem disposição e/ou capacidade para efetuar avaliações de ordem sistêmica em relação ao que vem ocorrendo e, por outro lado, a evidência de que o pouco que é feito, muitas vezes, estar impregnado de triunfalismo e excessivo otimismo. Espero que este artigo tenha contribuído para que tenhamos outros enfoques sobre o tema.

\section{REFERÊNCIAS}

ARELARO, L. R. G.; BARRETTO, E. S. S. A municipalização do ensino de $1^{\circ}$ grau: tese controvertida. Revista da Faculdade de Educação - FEUSP, São Paulo, v. 11, p. 193-210, 1985.

BASSI, M. E.; GIL, I. J. P. C. (Org.). A municipalização do ensino no estado de São Paulo: Impactos do Fundef no atendimento municipal. São Paulo: Ação Educativa, 1999. 222 p. Relatório Final.

BRASIL. Lei n. 9.424/96 - Fundo de Manutenção e Desenvolvimento do Ensino Fundamental e de Valorização do Magistério. Diário Oficial da União, 26 dez. 1996.

CARNOY, M.; McEWAN, P. J. Is Private Education More Effective and Cost-Effective than Public? The Case of Chile. [S. 1.]:Stanford University, 1998. 
CASASSUS, J. Descentralização e desconcentração educacional na América Latina: fundamentos e crítica. Cadernos de Pesquisa, São Paulo: Fundação Carlos Chagas, n. 74, p. 11-18, ago. 1990.

COLEGIO DE PROFESORES DE CHILE. Primer Congreso Nacional de EducaciónSantiago, 1997. Informe Final. Mimeog.

EGAÑA, L.; MAGENDZO, A. El marco teorico-político del proceso de descentralización educativa (1973-1983). Santiago: PIIE, 1983.

EGAÑA, L. Entrevista realizada em junho de 1999. Santiago, 1999.

ESPÍNOLA, H. V. et al. Evaluación de la gestión municipal en educación en el contexto de la descentralización. Estudios Sociales, [S. 1.], n. 91, 1997.

. Descentralización del sistema escolar en Chile. Santiago: Centro de Investigación y Desarrollo de la Educación, 1991.

. El impacto de la descentralización sobre la educación gratuita en Chile. Serie Gestión Escolar, CIDE, Santiago, n. 1, 1995.

ESPINOZA, O.; GONZALEZ, L. E. La experiencia del proceso de desconcentración y descentralización educacional en Chile: 1974-1989. Santiago: PIIE, 1993.

GIL, I. J. P. C. O mito da descentralização do ensino: o caso chileno. São Paulo, 2000. Dissertação (Mestrado) - Faculdade de Educação da Universidade de São Paulo.

HÉVIA RIVAS, R. Entrevista realizada em junho de 1999. Santiago, 1999.

. Política de descentralización en la educación básica y média en América Latina. Santiago: (Estado del Arte). REDUC/UNESCO, 1991.

JARA, C. M. La noción de descentralización del Estado en Chile: 1925-1993. Santiago: PUC, 1995.

MARTINIC, S. Entrevista realizada em junho de 1999. Santiago, 1999.

MIDEPLAN. Encuesta Casen 1998. Santiago, 1998.

MINEDUC. Compendio de Información Estadística. Santiago, 1997.

NUÑEZ, I. Entrevista realizada em junho de 1999. Santiago, 1999.

OLIVEIRA, C. et al. Municipalização do ensino no Brasil. Belo Horizonte: Autêntica, 1999.

SADER, E. Chile (1818-1990): Da independência à redemocratização. São Paulo: Brasiliense, 1991. 
VARGAS, M. Entrevista realizada em junho de 1999. Santiago, 1999.

VÁZQUEZ SALAZAR, D. Impacto del financiamiento en el desarrollo de la Educación Municipal. Santiago: Colegio de Profesores de Chile, 1997.

. Entrevista realizada em junho de 1999. Santiago, 1999.

Texto recebido em 10 ago. 2003

Texto aprovado em 03 out. 2003 